\title{
Varicella-zoster virus infection in the Infectious Diseases Hospital, Sri Lanka U Welgama ${ }^{1}$, C Wickramasinghe ${ }^{1}$ and Jennifer Perera ${ }^{2}$
}

(Index words: Health care facilities, morbidity, mortality, varicella related complications)

\begin{abstract}
Objectives To determine the morbidity and mortality patterns of varicella and risk factors affecting its outcome, and the facilities available at the Infectious Diseases Hospital (IDH), Sri Lanka.

Methods A retrospective study on all patients admitted with varicella-zoster virus (VZV) infection to the IDH from August 2000 to July 2001. Data were collected from the hospital records.

Results Among the 1690 patients admitted during the study period, $1090(64.9 \%)$ were due to VZV infection. Nine hundred and eighty nine $(90.7 \%)$ had varicella and 101 (9.3\%) herpes zoster. Common complications were secondary bacterial infection $(62.1 \%)$, neurological complications $(3.4 \%)$, pneumonia $(9.1 \%)$ and carditis $(1.01 \%)$. They were significantly commoner in patients with coexisting diseases. Hospital stay was significantly shorter in patients who received early aciclovir, which was not available on a regular basis. Forty one patients died and mortality was highest in the elderly. The commonest cause of death was pneumonia.
\end{abstract}

Conclusions Varicella related complications are high in patients with coexisting diseases. Mortality rates are higher than reported elsewhere. Health care facilities available at IDH are quite inadequate, and should be improved.

\section{Introduction}

Varicella infections occur worldwide. In temperate countries, most cases occur in children under 10 years contributing to $80-90 \%$ of reported cases $[1,2]$. The virus spreads less readily in countries with tropical climates resulting in a higher rate of susceptibility to varicella in adults [3]. It is not a notifiable disease in Sri Lanka at present and data on its prevalence are not available.

A variety of complications involving the respiratory, cardiovascular, and central nervous system and skin may develop, especially in older subjects and in the immunocompromised. Mortality rates from varicella are low but increases with advancing age, pregnancy and decreasing immuno-competence [4,5]. Varicella pneumonia is the commonest cause of death [6]. The case fatality rate of neonatal varicella is reported to be between $20 \%$ and $30 \%$ [7]. Zoster is mainly a disease of adults, usually with a history of previous varicella infection. The incidence of zoster begins to increase in the fifth decade and is commoner in the immuno-compromised [4].

The objectives of our research were to study the morbidity and mortality patterns of VZV infection, risk factors affecting the outcome, and facilities available for management of patients at the Infectious Diseases Hospital (IDH), Sri Lanka. A retrospective study was done on all patients admitted with VZV infection to the IDH from August 2000 to July 2001. The data were collected from hospital records and included socio-demographic data, clinical features, complications and disease outcome. Analysis of data was carried out using EPIINFO version 6 software package.

\section{Results}

The total number of patients admitted to IDH during the study period was 1690 . Among these, 1090 patients had VZV infection (64.9\%), of whom 989 (90.7\%) had varicella (chickenpox) and $101(9.3 \%)$ herpes zoster.

Of the herpes zoster cases the majority, 61 (61.4\%), had involvement of the ophthalmic branch of the trigeminal nerve, and 58 (57.4\%) were reported as having mild corneal infection by an ophthalmic surgeon. The average age of patients with zoster was 44 years (range 14 to 85 ), and 56 were males. Secondary bacterial infection was found in 90 , the only complication detected in zoster patients. There were no fatalities.

The age of the 989 patients with varicella ranged from three days to 94 years, and the majority 687 (69.4\%), were between 11 and 40 years (mean 33.2). Males accounted for $65.1 \%$ (644/989). Of the $345(34.9 \%)$ female patients, 10 were pregnant and four had a period of amenorrhoea of over 36 weeks (range 7-40 weeks).

Secondary bacterial infection was the commonest $(614,62.1 \%)$ complication. An interesting, and hitherto unreported observation, was the development of an extensive varicella rash in people with other skin diseases, in whom the rash was more severe and clustered in the areas with diseased skin. Secondary bacterial infections were complicated by cellulitis in 136 and septicaemia in six as shown by positive blood cultures (Table 1). Some of these patients had applied local herbal remedies to the skin rash, the commonest being kohomba (Azadirachta indica) containing applications. Pneumonia was noted in

${ }^{1}$ Medical Officer, Infectious Diseases Hospital, ${ }^{2}$ Professor, Department of Microbiology, Faculty of Medicine, Colombo. Correspondence: JF, Department of Microbiology, Faculty of Medicine, Kynsey Road Colombo 8, Sri Lanka (Competing interests: none declared). Received 31 March and revised version accepted 13 July 2003. 
Table 1. Incidence of common complications in patients with varicella admitted to the IDH

\begin{tabular}{lc}
\hline Complication & $\begin{array}{c}\text { Number }(\%) \\
(\text { N=989) }\end{array}$ \\
\hline Secondary bacterial infection & $704(64.4)$ \\
Pneumonitis & $90(9.1)$ \\
Neurological manifestations & $34(3.4)$ \\
Carditis & $10(1.0)$ \\
\hline
\end{tabular}

Table 2. Varicella associated complications and significance in patients with co-morbidity

\begin{tabular}{lccc}
\hline Total number & $\begin{array}{c}\text { Alcoholic } \\
\text { liver disease } \\
n=108\end{array}$ & $\begin{array}{c}\text { Diabetes } \\
n=149\end{array}$ & $\begin{array}{c}\text { Immuno- } \\
\text { compromised } \\
n=35\end{array}$ \\
\hline $\begin{array}{l}\text { Carditis } \\
(\mathrm{n}=10)\end{array}$ & 3 & 3 & 2 \\
$(\mathrm{p}=0.03)$ & $(\mathrm{p}=0.13)$ & $(\mathrm{p}=0.007)$ \\
$\begin{array}{l}\text { Pneumonitis } \\
(\mathrm{n}=90)\end{array}$ & 38 & 34 & 4 \\
$(\mathrm{p}=0.0001)$ & $(\mathrm{p}=0.0001)$ & $(\mathrm{p}=0.41)$ \\
$\begin{array}{l}\text { Neurological } \\
\text { manifestations } \\
(\mathrm{n}=34)\end{array}$ & 17 & 11 & \\
& $(\mathrm{p}=0.0001)$ & $(\mathrm{p}=0.0005)$ & \\
$\begin{array}{l}\text { Haemorrhagic } \\
\text { skin lesions/cellulitis } \\
(\mathrm{n}=142)\end{array}$ & $\begin{array}{c}40 \\
(\mathrm{p}=0.009)\end{array}$ & $\begin{array}{l}(\mathrm{p}=0.00003) \\
(\mathrm{p}=0.19)\end{array}$ \\
\hline
\end{tabular}

$90(9.1 \%)$, as determined by tachypnoea (respiratory rate $>30 / \mathrm{min}$ ) and an oxygen saturation of less than $80 \%$ on pulse oximetry. Some had cyanosis, a high white cell count with lymphocytosis and inflammatory changes in the chest $\mathrm{x}$-ray. $\mathrm{x}$-Ray facilities were not available for all patients as the unit was shared between the Mental Hospital and IDH. Carditis occurred in $10(1.0 \%)$ patients and all had chest pain, suggestive ECG changes (low voltage complexes, diffuse ST elevation in most leads, PR segment depression), tachycardia (pulse rate $>110 /$ min) and hypotension. Neurological complications occurred in $34(3.4 \%)$ and symptoms included neck stiffness, drowsiness, confusion in all patients, with some patients having in addition restlessness, CSF lymphocytosis or cerebellar signs.

Complications were significantly more in patients with coexisting diseases (234/338) such as diabetes mellitus, skin diseases, bronchial asthma, immunosuppression and alcoholic liver disease, compared to patients who did not have them $(42 / 651)(\mathrm{p}<0.01)$. One hundred and forty nine patients were diabetic. Of them $128(85.9 \%)$ developed an extensive rash, 34 (22.8\%) had pneumonia, $11(7.4 \%)$ had neurological involvement and $12(8.1 \%)$ died. Of the 33 patients with varicella from the Cancer Institute, Maharagama, who were on immunosuppressive chemotherapy, the majority were transferred to the IDH on the first day of vesiculation. Of them, only two died in spite of their low immune status, probably due to early intervention with intravenous aciclovir therapy. Of the two patients who had renal transplants, one died from septicaemia and pneumonia. Among the 108 patients with alcoholic liver disease, 90 (83.3\%) developed an extensive rash, $17(0.9 \%)$ had neurological manifestations, 38 $(35.1 \%)$ developed lung complications and 18 (16.7\%) died. Table 2 provides a summary of these findings. Table 3 shows that there was a correlation between the day of admission after appearance of the rash and development of some complications.

Of the 989 varicella patients 41 (4.15\%) died of varicella related complications. The average age of patients who died was 67.1 years whereas the average age of the patient population with varicella was 33.2 years. The difference was statistically significant $(\mathrm{p}<0.01)$. Thirteen patients died at IDH and 11 had pneumonia. Of the 54 who were transferred to National Hospital of Sri Lanka (NHSL) for specialised care, 28 succumbed to the disease and the cause of death could not be verified. The final outcome of disease in the other 26 patients at NHSL could not be found. The mortality had a correlation with date of admission after vesiculation (Table 4).

Table 3. Percentage of complications in relation to date of admission (DOA) after development of rash

\begin{tabular}{lccccccccccc}
\hline & \multicolumn{10}{c}{ DOA after development of rash } \\
\cline { 2 - 11 } & 1 & 2 & 3 & 4 & 5 & 6 & 7 & 8 & 9 & $\geq 10$ \\
\hline Pneumonitis & 1.9 & 3.8 & 5.2 & 11.2 & 19.2 & 21.6 & 41.2 & 6.2 & 7.2 & 0 \\
Neurological & 0.46 & 0.7 & 0.9 & 0.8 & 4.8 & 10 & 13.1 & 12 & 31 & 23 \\
Carditis & 0 & 0.3 & 0.9 & 0 & 3.3 & 3.3 & 0 & 0 & 0 & 4.2 \\
Bacterial infections & 34.2 & 45.3 & 64.4 & 88 & 93.6 & 98.3 & 100 & 100 & 98 & 100 \\
\hline
\end{tabular}


Table 4. Association between date of admission after vesiculation and mortality in varicella patients

\begin{tabular}{lcr}
\hline $\begin{array}{l}\text { Duration of } \\
\text { rash (days) }\end{array}$ & $\begin{array}{c}\text { Number admitted } \\
\text { to IDH }\end{array}$ & $\begin{array}{l}\text { Number of } \\
\text { deaths }(\%)\end{array}$ \\
\hline 1 & 216 & 0 \\
2 & 260 & $3(0.4)$ \\
3 & 208 & $3(1.4)$ \\
4 & 125 & $6(4.8)$ \\
5 & 125 & $9(7.2)$ \\
6 & 60 & $13(21.7)$ \\
7 & 46 & $3(6.5)$ \\
8 & 16 & 0 \\
9 & 13 & $4(30.8)$ \\
$\geq 10$ & 21 & $2(9.5)$ \\
\hline
\end{tabular}

As for specific treatment, $503(50.8 \%)$ patients received oral, and $140(14.2 \%)$ intravenous aciclovir. Among the 684 patients who were admitted within $72 \mathrm{~h}$ of the onset of rash, 328 received aciclovir and their mean duration of stay was 5.9 days compared to 8.1 days in the remaining 356, who did not receive aciclovir due to nonavailability of the drug. Among the 711 patients who received antibiotics 434 were given oral and 277 intravenous antibiotics.

\section{Discussion}

Varicella was the commonest disease treated at the IDH. In tropical countries varicella is reportedly more prevalent in early adulthood and our findings confirm this.

It was found to be a significant cause of morbidity and mortality among the elderly and patients with comorbid conditions. The day of admission after vesiculation and aciclovir therapy significantly correlated with the development of complications and eventual outcome. The commonest varicella related complication was secondary bacterial infection. The application of nonsterile traditional remedies, poor hygiene or nosocomial infections during the hospital stay were likely contributory factors. The main cause of death following varicella was pneumonia. With the available data we could not ascertain whether the pneumonia was due to primary viral infection or secondary bacterial infection. The complications are similar to those reported in earlier studies although incidence and severity are higher in ours [8].

The patients who received aciclovir within $72 \mathrm{~h}$ of the rash had a significantly shorter hospital stay with early discharge compared to those who did not receive it. Hence a regular supply of aciclovir is a basic requirement. The cost of $200 \mathrm{mg}$ of generic aciclovir is only Rs 6 and of the standard oral course will be about Rs 600. Aciclovir will lower the cost of management of patients by reducing complications, hospital stay and specialised treatment.

Seriously ill patients were transferred to a specialised unit in the NHSL as neither intensive care facilities nor supervision of a consultant physician was available during the period of study. The IDH does not have an ambulance, and the vehicle of the Mental Hospital was used for transfer of patients to the NHSL. The IDH badly needs an ambulance, intensive care facility, in-house x-ray unit, and a regular supply of aciclovir.

The economic impact of varicella on lost work days for both patients and carers at home are also likely to be substantial. Prevention by vaccination is a cost effective approach to minimise the impact of varicella on high risk groups such as diabetics, organ transplant recipients and patients undergoing anticancer therapy.

\section{Acknowledgement}

We thank Ms Shirani Hendalage for secretarial assistance.

\section{References}

1. Ross AH, Lencher E, Reitman G. Modification of chickenpox in family contacts by administration of gamma globulin. New England Journal of Medicine 1962; 267: 369-76.

2. Preblud SR. Varicella: complications and costs. Paediatrics (supplement) 1986: 76: 728-35.

3. Kjersem H, Jepsen S. Varicella among immigrants from the tropics, a health problem. Scandinavian Journal of Social Medicine 1990; 18: 171-4.

4. Gershon A, Silverstein S. Varicella zoster virus. In: Richman DD, Whitley RJ, Hayden FG, eds. Clinical Virology. London: Churchill Livingstone, 1997.

5. Johnson R, Milbourn PE. Central nervous system manifestations of chickenpox. Canadian Medical Association Journal 1970; 102: 831-4.

6. Meyer PA, Seward JE, Jumaan AO, Wharton M. Varicella mortality: trends before vaccine licensure in the United States 1970-1994. Journal of Infectious Diseases 2000; 182: 383-90.

7. Gilbert GL. Varicella. In: Lanzkowsky P, ed. Monographs in Clinical Paediatrics. Infectious Diseases in Pregnancy and the Newborn Infant. Amsterdam: Harwood Academic Publishers, 1991; 339-47.

8. Somekh E, Marashak N, Shapira Y, Greenberg D, Dagan VT. Hospitalization for primary varicella zoster virus infection and its complications in patients from Southern Israel. Infection 2000; 28: 200-4. 